\title{
A PEDAGOGIA HISTÓRICO-CRÍTICA E SUAS POSSIBILIDADES PARA A PROMOÇÃO DO SABER ELABORADO
}

\author{
Geuciane Felipe Guerim Fernandes ${ }^{1}$, Sandra Aparecida Pires Franco ${ }^{2}$ \\ ${ }^{1}$ Mestre em Educação pela Universidade Estadual de Londrina (UEL), Londrina-PR. Atualmente é professora \\ colaboradora na Universidade Estadual do Norte do Paraná (UENP) e Pedagoga da Secretaria de Educação do Estado \\ do Paraná. E-mail: geu tc@hotmail.com \\ ${ }^{2}$ Doutora em Letras pela Universidade Estadual de Londrina (UEL); Possui Pós-doutorado em Educação pela \\ Universidade Estadual Paulista (UNESP), campus de Marília, SP. Atualmente é professora adjunta do Departamento de \\ Educação e do Programa de Pós-Graduação em Educação da Universidade Estadual de Londrina (UEL).
}

\section{RESUMO}

Este artigo tem como objetivo principal apresentar elementos fundamentais para refletir sobre o papel da educação na sociedade contemporânea e as possibilidades da Pedagogia Histórico-Crítica na promoção do saber elaborado. As análises foram contextualizadas a partir de uma pesquisa bibliográfica, fundamentada na concepção de homem do Materialismo Histórico-Dialético, bem como nos fundamentos da educação preconizados pela Pedagogia Histórico-Crítica. Pensar na formação humana por meio do trabalho educativo, como ato de produzir direta e intencionalmente nos alunos a humanidade produzida historicamente pelo conjunto dos homens, pressupõe uma fundamentação que eleve o sujeito à apropriação da cultura elaborada historicamente, o que pode vislumbrar uma nova percepção da sua realidade social.

Palavras-chave: Pedagogia Histórico-Crítica; Materialismo Histórico-Dialético; saber elaborado; formação humana.

\section{THE HISTORICAL-CRITICAL PEDAGOGY AND ITS POSSIBILITIES FOR THE PROMOTION OF THE ELABORATED KNOWLEDGE}

\begin{abstract}
This article has as main objective to present fundamental elements to reflect on the role of education in contemporary society and the possibilities of Historical-Critical Pedagogy in the promotion of elaborated knowledge. The analyzes were contextualized based on a bibliographical research, based on the conception of man of Historical-Dialectical Materialism, as well as on the objectives of education advocated by Historical-Critical Pedagogy. To think of human formation through educational work, as an act of producing directly and intentionally in the students the humanity produced historically by all men, presupposes a foundation that elevates the subject to the appropriation of the culture elaborated historically, which can glimpse a new perception of the their social reality.
\end{abstract}

Keywords: Historical-Critical Pedagogy; Historical-Dialectical Materialism; elaborate knowledge; human formation.

\section{LA PEDAGOGIA HISTORICA-CRITICA Y SUS POSIBILIDADES PARA LA PROMOCION DEL CONOCIMIENTO ELABORADO}

Resumen: Este artículo tiene como objetivo principal presentar elementos fundamentales para reflexionar sobre el papel de la educación en la sociedad contemporánea y las posibilidades de la Pedagogía HistóricoCrítica en la promoción del saber elaborado. Los análisis fueron contextualizados a partir de una 
investigación bibliográfica, fundamentada en la concepción de hombre del Materialismo HistóricoDialéctico, así como en los objetivos de la educación preconizados por la Pedagogía Histórico-Crítica. Pensar en la formación humana por medio del trabajo educativo, como acto de producir directa e intencionalmente en los alumnos la humanidad producida históricamente por el conjunto de los hombres, presupone una fundamentación que eleve al sujeto a la apropiación de la cultura elaborada históricamente, lo que puede vislumbrar una nueva percepción de la cultura, su realidad social.

Palabras clave: Pedagogía Histórico-Crítica; Materialismo histórico-dialéctico; el saber elaborado; formación humana.

\section{INTRODUÇÃO}

Este artigo tem como objetivo principal apresentar elementos fundamentais para refletirmos sobre o papel da educação na sociedade contemporânea e as possibilidades da Pedagogia Histórico-Crítica na promoção do saber elaborado. Marx e Engels (2007, p. 19) afirmam que os homens "são condicionados por um determinado desenvolvimento de suas forças produtivas e das relações que a elas corresponde [...]". Aquilo que os indivíduos são depende diretamente das condições materiais de sua produção.

Neste sentido, consideramos pertinente situar o trabalho no mundo capitalista e seus efeitos sobre o desenvolvimento humano, para que possamos pensar no Materialismo HistóricoDialético como método de análise desta sociedade como um todo, sendo a educação uma dimensão da prática social. Do mesmo modo, pensar nesta totalidade pressupõe uma teoria da educação que esteja comprometida com a história e a produção humana, revelando seus significados e possibilitando aos alunos desenvolver-se conscientemente. Para isso, contamos com as contribuições da Pedagogia Histórico-Crítica.

\section{DELINEAMENTO METODOLÓGICO}

As análises foram contextualizadas a partir de uma pesquisa bibliográfica, fundamentada na concepção de homem do Materialismo Histórico-Dialético, bem como nos objetivos da educação preconizados pela Pedagogia Histórico-Crítica. As investigações foram realizadas à luz da perspectiva críticodialética (GAMBOA, 2011), no sentido de abordar os aspectos da realidade estudada em sua totalidade.

O surgimento do Marxismo é resultado do próprio desenvolvimento da humanidade, especificamente das necessidades humanas frente à sociedade capitalista. O Materialismo Histórico-Dialético, concepção filosófica do Marxismo, constitui-se um método de análise que busca compreender a realidade social a partir de sua base material, ou seja, um método científico da realidade que, somado à prática social dos homens, busca propor apontamentos de superação para a realidade social.

$\mathrm{Em}$ "Introdução ao estudo do método de Marx", Paulo Netto (2011) reconstrói a longa trajetória acadêmica de Marx, apontando como início do seu pensamento original o período de 1843 e 1844, quando ao se confrontar com a filosofia de Hegel, Marx direciona seus estudos e pesquisas para a análise concreta da sociedade moderna: a sociedade burguesa. Neste sentido, "A obra de Marx não surge como um raio inesperado em céu sereno." (PAULO NETTO, 2006 , p. 22), mas como resposta aos problemas colocados pela sociedade burguesa e uma possibilidade de intervenção para a classe operária.

Neste artigo, as principais obras que fundamentaram a pesquisa bibliográfica são as que apresentam a concepção de homem do Materialismo Histórico-Dialético (ENGELS, 1876; MARX; ENGELS, 2007; MARX, 1996a, 1996b, 2004, 2008a, 2008b; 2010; PAULO NETTO, 2006), bem como os objetivos da educação preconizados pela Pedagogia Histórico-Crítica (DUARTE, 2008, 2011, 2015; SAVIANI, 2007, 2008, 2009, 2011, 2012). O artigo foi direcionado à luz da perspectiva crítico-dialética, no sentido de abordar os aspectos da realidade estudada em sua totalidade. Para isso, organizamos a pesquisa em três categorias principais. Em "Trabalho e educação: um processo histórico da produção humana", enfatizamos que a educação se origina e se desenvolve mediante a produção de vida material do homem, por isso, a importância de 
conhecer a realidade social como está posta e os objetivos a que ela se propõe, pois a escola pode tanto reiterar o sistema de exploração como pode fornecer elementos de superação. Em "O Materialismo Histórico-Dialético: possibilidades para a análise e compreensão da realidade social", buscamos compreender a relevância do Materialismo Histórico-Dialético para pensarmos a situação atual e a perspectiva de totalidade na educação, preconizada pela Pedagogia HistóricoCrítica, uma teoria comprometida com a socialização do conhecimento historicamente acumulado, que defende, como papel da escola, identificar os elementos que precisam ser assimilados pelos alunos e, concomitantemente, desenvolver formas adequadas para sua apropriação. Nas "conclusões" retomamos os principais pontos de discussão presentes no artigo, a fim de ressaltar a importância de um ensino que garanta aos alunos o direito inalienável aos bens culturais produzidos pela humanidade, para que, por intermédio do conhecimento, possam desenvolver-se e, com isso, humanizar-se, no sentido de compreender as contradições da sociedade e intervir sobre elas, edificando a prática social como sujeito construtor da história humana.

\section{TRABALHO E EDUCAÇÃO: UM PROCESSO HISTÓRICO DA PRODUÇÃO HUMANA}

O desenvolvimento histórico e social está atrelado diretamente à produção da materialidade humana, em que o trabalho apresenta-se como atividade de mediação entre o homem e a natureza, derivando assim todo o processo de formação humana. Neste sentido, o trabalho é entendido como o primeiro fato histórico da produção do homem "[...] uma condição fundamental de toda a história que se deve, ainda hoje como há milhares de anos, preencher dia a dia, hora a hora, simplesmente para manter os homens com vida." (MARX; ENGELS, 2007, p.21). Diferente dos outros animais que garantem sua existência naturalmente por meio da adaptação à realidade natural, o homem precisa produzir sua existência por meio do trabalho, construindo uma segunda natureza de origem social e produzida historicamente (MARX; ENGELS, 2007).

O trabalho constitui-se assim a criação de meios para a satisfação das necessidades humanas. Ao satisfazer a primeira necessidade, a própria ação de satisfazê-la leva a novas necessidades, "[...] e essa produção de novas necessidades é o primeiro ato histórico" (MARX; ENGELS, 2007, p. 22). O ponto de partida da história consiste na existência de seres humanos reais que estabelecem relações pela e na sociedade, humanizando-se em um processo dialético de conhecimento, apreendido sob as condições reais da produção humana constituída pelo trabalho (MARX, 1996a, 1996b, 2004). Em Marx e Engels (2007, p. 25), " [...] a consciência da necessidade de entrar em relação com os indivíduos que o cercam marca, para o homem, o começo da consciência do fato de que, afinal, ele vive em sociedade [...]." Assim, sua consciência se aperfeiçoa conforme sua produção, pelo aumento de suas necessidades.

Em face de cada novo progresso, o domínio sobre a natureza que tivera início com o desenvolvimento da mão, com o trabalho, ia ampliando os horizontes do homem, levando-o a descobrir constantemente nos objetos novas propriedades até então desconhecidas. Por outro lado, o desenvolvimento do trabalho, ao multiplicar os casos de ajuda mútua e de atividade conjunta, e ao mostrar assim as vantagens dessa atividade conjunta para cada indivíduo, tinha que contribuir forçosamente para agrupar ainda mais os membros da sociedade. Em resumo, os homens em formação chegaram a um ponto em que tiveram necessidade de dizer algo uns aos outros. A necessidade criou o órgão: a laringe pouco desenvolvida do macaco foi-se transformando, lenta mas firmemente, mediante modulações que produziam por sua vez modulações mais perfeitas, enquanto os órgãos da boca aprendiam pouco a pouco a pronunciar um som articulado após outro. (ENGELS, 1876, p. 4-5). 
Engels (1876) afirma que o desenvolvimento do trabalho e das necessidades advindas dele impulsionou o aperfeiçoamento da mão, da linguagem, do cérebro, possibilitando ao homem aprender a executar operações cada vez mais complexas, como por exemplo, dar vida a uma obra de arte. Assim, o trabalho foi aperfeiçoando-se de geração em geração. Engels (1876) aponta que à caça e à pesca juntou-se a agricultura, e assim continuadamente a fiação, a tecelagem, a elaboração de metais, olaria e navegação. No trabalho surgiu a arte, a ciência e das tribos, as nações e estados. Ao desenvolver sua natureza social e objetiva, o homem continua a avançar impulsionado e orientando pelas relações sociais. Desta forma, ao adquirir novas forças produtivas, o homem transforma o seu modo de produção e ao transformá-lo, altera também suas relações sociais. "O desenvolvimento do cérebro e dos sentidos a seu serviço, a crescente clareza de consciência, a capacidade de abstração e de discernimento cada vez maiores, reagiram por sua vez sobre o trabalho e a palavra, estimulando mais e mais o seu desenvolvimento" (ENGELS, 1876, p. 6-7).

O trabalho é um processo histórico da produção humana, no qual o homem produz a sua existência e desenvolve o ser social pela criação de meios para a satisfação de suas necessidades. A riqueza do homem é simultaneamente a necessidade de uma totalidade da vida humana, o homem no qual sua própria efetivação existe como necessidade (MARX, 2004; MARX; ENGELS, 2007). Nessa direção, concebido como objetivação da espécie humana, o trabalho diferencia-se da atividade animal. A produção de um mundo objetivo é a confirmação do homem como um ser social.

O processo de apropriação surge, antes de tudo, na relação entre o homem e a natureza. O ser humano, pela sua atividade transformadora, apropriase da natureza incorporando-a à prática social. Ao mesmo tempo, ocorre também o processo de objetivação: o ser humano produz uma realidade objetiva que passa a ser portadora de características humanas, pois adquire características socioculturais, acumulando a atividade de gerações de seres humanos. Isso gera a necessidade de outra forma do processo de apropriação, já agora não mais apenas como apropriação da natureza, mas como apropriação dos produtos culturais da atividade humana, isto é, apropriação das objetivações do gênero humano (entendidas aqui como os produtos da atividade objetivadora) (DUARTE, 2008, p. 24).

Na sociedade primitiva esta relação era demonstrada naturalmente por meio da apropriação coletiva dos meios de produção. 0 resultado da aprendizagem do trabalho humano desenvolvido coletivamente possibilitava a educação de todos e para todos, pela transmissão e reprodução do conhecimento acumulado. Nisso consiste o que Saviani (2007) sugere como fundamentos histórico-ontológicos da relação trabalho-educação. Histórico, pois o desenvolvimento do homem se dá na e pela história com a ação dos próprios homens e ontológicos porque o resultado de sua ação é o ser dos homens, o modo de sua produção, sua essência (SAVIANI, 2007).

Com o desenvolvimento das forças primitivas e a apropriação privada das terras, a sociedade primitiva, até então homogênea, passa a dividir-se em classes antagônicas, modificando o modo de produzir a existência humana e, consequentemente, o processo educativo, na separação entre trabalho e educação, trabalho material e intelectual, configurando assim, duas classes sociais fundamentais: a classe dos proprietários e a dos não proprietários, em que alguns homens trabalham e outros se apropriam do trabalho daqueles. A constituição de classes sociais resultou na formação da desigualdade no interior da sociedade, circunscrita na constante luta de classes, da divisão em grupos sociais distintos, com interesses econômicos opostos (SAVIANI, 2007).

No modo de produção capitalista, ocorre uma significativa mudança no trabalho e na produção humana. A objetivação do gênero humano torna-se estranha ao próprio homem, 
pois nesta sociedade o homem apropria-se de forma fragmentada de sua criação, de sua atividade e do objeto do seu trabalho. 0 produtor já não domina suas forças produtivas, a fonte de riqueza torna-se a propriedade dos meios de produção, em que uma minoria constitui a classe burguesa e a maioria da população a classe trabalhadora, que transforma sua mão de obra em mercadoria que resulta no salário (MARX, 1996b; 2004).

O trabalhador se torna tanto mais pobre quanto mais riqueza produz, quanto mais a sua produção aumenta em poder e extensão. 0 trabalhador se torna uma mercadoria tão mais barata quanto mais mercadorias cria. Com a valorização do mundo das coisas aumenta em proporção direta a desvalorização do mundo dos homens (MARX, 2004, p. 80).

Na medida em que a natureza se tornou estranha ao trabalhador, o homem torna-se estranho ao seu próprio gênero e essência humana. Marx (2004) aponta, neste sentido, que a apropriação do objeto aparece ao homem como estranhamento, pois quanto mais ele produz menos pode possuir e mais fica sob o domínio do capital. Assim, "[...] quanto mais o trabalhador se desgasta trabalhando, tanto mais poderoso se torna o mundo objetivo, alheio que ele cria diante de si, tanto mais pobre se torna ele mesmo, seu mundo interior e tanto menos o trabalhador pertence a si próprio" (MARX, 2004, p. 81).

Marx (2004) afirma neste sentido, que com a perda de si mesmo o trabalho torna-se externo ao produtor, impossibilitando o exercício de uma atividade consciente. Este estranhamento empobrece o ser humano, pois quanto mais poderoso se torna o trabalho, mais pobre e servo da natureza se torna o trabalhador.

Primeiro, que o trabalho é externo ao trabalhador, isto é, não pertence ao seu ser, que ele não se afirma, portanto, em seu trabalho, mas nega-se nele, que não se sente bem, mas infeliz [...]. O trabalhador só se sente, por conseguinte $\mathrm{e}$ em primeiro lugar, junto a si [quando] fora do trabalho e fora de si [quando no trabalho]. 0 trabalho não é, por isso, a satisfação de uma carência. Mas somente um meio para satisfazer necessidades fora dele (MARX, 2004, p. 82-83).

Nesse movimento, reside à própria contradição do sistema capitalista que impede o ser humano de desenvolver-se plenamente, pois há uma separação posta entre o produto do trabalho e o próprio trabalhador: o produto do trabalho transforma-se em capital, "[...] em valor que explora a força criadora de valor, em meios de subsistência que compram pessoas, em meios de produção que empregam o produtor." Por outro lado "[...] o trabalhador sai do processo sempre como nele entrou - fonte pessoal de riqueza, mas despojado de todos os meios, para tornar essa riqueza realidade para si" (MARX, 1996b, p. 203-204). "Chega-se, por conseguinte, ao resultado de que o homem (o trabalhador) só se sente como [ser] livre e ativo em suas funções animais, comer, beber e procriar, quando muito ainda habitação, adornos, etc., e em suas funções humanas só [se sente] como animal" (MARX, 2004, p. 83).

Marx (2004) afirma que o lugar dos sentidos humanos produzidos pela atividade principal, o trabalho, passou a ser ocupado pelo simples estranhamento de todos esses sentidos, pelo sentido do ter. A essência humana do ser social reduziu-se ao homem enquanto uma mercadoria, algo estranho a si mesmo. "Na medida em que o trabalho estranhado estranha do homem a natureza e o homem de si mesmo, de sua própria função ativa, de sua atividade vital, ele estranha do homem o gênero humano" (MARX, 2004, p. 86), pois a consciência do gênero humano torna-se meio apenas para sua sobrevivência individual, a fim de manter-se vivo fisicamente.

Com esta visão utilitarista preconizada pela situação econômica atual, o trabalho que ora seria a atividade vital, torna-se estranho e externo à formação e desenvolvimento do sujeito, impossibilitando a apropriação total das objetivações humanas. Sem esta possibilidade, o homem fica restrito ao desenvolvimento material, não exercendo, na maioria das vezes, a 
atividade de apropriação do conhecimento, habilidades e valores que possibilitaria desenvolver-se enquanto ser humano.

Se a origem da educação se coincide com a própria origem do homem, as mudanças no modo de produção humana foram alterando a relação entre o trabalho e educação. Com o desenvolvimento capitalista, a escola foi constituindo-se como instituição de formação para o trabalho e de reprodução de classes, assim:

[...] Se, por um lado, o trabalhador precisa ter acesso a conhecimentos; por outro, esses conhecimentos não podem levar a questionamentos que atrapalhem a ascensão da burguesia. É necessário então formar um trabalhador que se submeta aos ditames do capital (e os aceite) e que se ajuste a essa forma de trabalho, a saber, o trabalho assalariado (RUIZ, 2014, p. 127).

A escola, portanto, caracteriza-se como um espaço contraditório de confrontos de forças sociais antagônicas. Enquanto para a burguesia, o conhecimento se constituiu como instrumento de perpetuação do domínio mediante a formação do espírito produtivo, para o trabalhador se apresenta como uma possibilidade de libertação mediante a difusão do conhecimento, isto é, a libertação da consciência para a emancipação do homem (CAMBI, 1999; RUIZ, 2014).

Assim, a função ideológica da sociedade de classes se organiza a fim de distanciar a busca por práticas educativas que possibilitem o pensamento crítico e a superação da sociedade capitalista, e por meio de questões ditas "atuais", a escola se desvincula da sua real função e promove práticas que reafirmam a vida e os problemas cotidianos na educação, limitando-se a práticas fragmentadas, que se expressam nos conteúdos, métodos e organização da escola (DUARTE, 2008).

Com esta ilusão, muitas práticas educativas têm sido reduzidas a busca por resultados imediatos, que visam meras competências para a adaptação do aluno à vida social e produtiva do capitalismo. Assim, há uma fragmentação entre o conhecimento científico e o saber prático, aspecto que contribui ainda mais para a alienação do indivíduo frente a este tipo de sociedade. Aos educadores, a função do trabalho educativo resume-se em conhecer as competências necessárias para a formação do indivíduo frente às exigências do capital, quando na verdade à função social da escola caberia conhecer a realidade social, refletir sobre ela e por meio do conhecimento historicamente elaborado, buscar formas adequadas de ensino e aprendizagem que estejam comprometidas com a transformação social (LOMBARDI; SAVIANI; SANFELICE, 2002; DUARTE, 2008; SAVIANI, 2011).

Saviani (2008) aponta que os mecanismos acionados como meio de adaptação aos anseios capitalistas podem ser confundidos como anseios da classe dominada. Neste sentido, enfatiza a necessidade de avançar na compreensão da natureza específica da educação e de suas complexas mediações que se inserem contraditoriamente na sociedade capitalista. Trata-se de engajar-se na luta contra a seletividade, discriminação e o rebaixamento do ensino às camadas populares. Isto significa que a escola, por meio de sua função própria de socialização do conhecimento elaborado exercida pelos professores, tem condições efetivas de garantir aos trabalhadores um ensino de melhor qualidade, possível dentro das condições históricas atuais.

Tomada como dimensão da própria prática social, uma educação comprometida em viabilizar o saber elaborado em sua totalidade, busca pelas esferas do saber, empreender "a crítica à educação burguesa evidenciando seus mecanismos e desmistificando sua justificação ideológica" (SAVIANI, 2009, p. 114) e ao mesmo tempo "reorganizar a prática educativa de modo a viabilizar, por parte das camadas dominadas à frente 0 proletariado, 0 acesso ao saber elaborado" (SAVIANI, 2009, p. 114).

Esta perspectiva tem como contribuição teórica e metodológica o Materialismo HistóricoDialético. Os fundamentos preconizados por Marx (1996a, 1996b, 2004, 2008a) tornaram-se fundamentais para as ciências humanas na contemporaneidade, no intuito de afirmar a perspectiva da totalidade como fator primordial para compreender o conhecimento como uma rica totalidade de múltiplas determinações e relações diversas. 


\section{O MATERIALISMO HISTÓRICO-DIALÉTICO: POSSIBILIDADES PARA A ANÁLISE E COMPREENSÃO DA REALIDADE SOCIAL}

Ao tratar dos pressupostos da teoria social de Marx, Paulo Netto (2006) aponta que no início do século XIX com o delineamento da sociedade burguesa surgem grandes mudanças na organização e na produção de bens, movimento chamado de Revolução Industrial, que se traduz em um mundo novo, no qual o conhecimento científico relaciona-se diretamente com os modos de produção, "a economia e a sociedade são organizadas de modo particular, submetidas ambas a uma estratégia global (a da burguesia) e a uma lógica específica (a da valorização do capital)" (PAULO NETTO, 2006, p.11). Inspirados em uma concepção capitalista, o mundo burguês se desenvolve e, com isso, impulsiona também o pensamento humano que traz como possibilidade de emancipação a Revolução Proletária.

O movimento dos trabalhadores se dá em busca de um projeto político socialista que supere a sociedade burguesa, a alienação e exploração capitalista (PAULO NETTO, 2006). “Na sociedade burguesa, o trabalho vivo constitui-se apenas para multiplicar o trabalho acumulado. Na sociedade comunista, o trabalho acumulado é apenas um meio para ampliar, enriquecer e incentivar a existência do trabalhador." (MARX, 2008b, p. 33). Este movimento pressupõe o despertar da consciência de classe.

Com o atraso da sociedade alemã, houve nesse tempo um desenvolvimento intenso da Filosofia, sendo as obras de Hegel, amplamente debatidas. O princípio fundamental do idealismo de Hegel refere-se à questão do ser e do pensamento, sendo que o mundo real deve ser compreendido como uma manifestação do espírito (ANDERY; SÉRIO, 1994). Sendo assim, constituía-se a ideia como fator primário e a matéria fator secundário na compreensão da realidade.

A fim de superar o pensamento de Hegel, que tratava a dialética a partir do ideal, sendo este o criador do real e o real apenas sua manifestação externa, Marx e Engels (2007) buscaram propor a dialética a partir de suas bases materiais e, assim, compreender a sociedade burguesa para suprimi-la. Marx (1996a) aponta que seu método dialético é a antítese da dialética de Hegel. Para ele, a dialética se constituía de caráter materialista e histórico, em que "[...] o ideal não é nada mais que o material, transposto e traduzido na cabeça do homem (MARX, 1996a, p. 55). Assim, ao tratar sobre a realidade do homem, de sua prática social, a análise deveria partir da existência dos próprios homens "[...] na sua existência real, isto é, tais como trabalham e produzem materialmente [...]" (MARX; ENGELS, 2007, p. 18). É esse caráter materialista e histórico que traduz a diferença entre o Marxismo e a filosofia Alemã: "A consciência nunca pode ser mais que o ser consciente, e o ser dos homens é o seu processo de vida real" (MARX; ENGELS, 2007, p. 19).

Ao contrário da filosofia alemã, [...] não partimos do que os homens dizem, imaginam e representam, tampouco do que eles são nas palavras, no pensamento, na imaginação e na representação dos outros, para depois se chegar aos homens de carne e osso; mas partimos dos homens em sua atividade real [...] (MARX; ENGELS, 2007, p. 19).

Partindo da materialidade pela qual os homens se constituem como ser social, Marx e Engels (2007, p. 19-20) destacam que "[...] são os homens que, desenvolvendo sua produção material e suas relações materiais, transformam, com a realidade que lhes é própria, seu pensamento e os produtos do seu pensamento". Nesse caminho, contrapondo-se a visão hegeliana de abordagem idealista, buscaram compreender as condições materiais da existência social dos homens a partir do funcionamento da ordem social burguesa, a fim de anunciar as possibilidades de uma sociedade futura.

Hegel via o Estado como um momento harmônico dos interesses da sociedade civil, Marx o contrapôs e desacreditava que o Estado seria uma entidade representativa dos interesses comuns da sociedade. Para ele havia uma separação entre a sociedade Civil e o Estado, sendo o Estado uma alienação da sociedade civil, onde os indivíduos não exercem seu poder de decisão diretamente e alienam esse poder ao Estado, que, ao se vestir de uma aparência ideológica, vincula-se diretamente à classe dominante e seus interesses. $O$ Estado constituído pela força e cooperação entre os homens gera um poder social alienado, fora do 
controle dos próprios homens. Para Marx (2010), a sociedade civil deveria se apresentar como o próprio Estado, sendo o verdadeiro cenário da história (MARX; ENGELS, 2007; MARX, 2010).

Para Marx (2010) superar a alienação implicaria tomar nas mãos o poder decisório por meio da democracia, e esta, possibilitaria à sociedade civil libertar-se das divisões de classes. Em sua concepção, o encontro entre a filosofia e o proletariado é o que viabilizaria uma verdadeira revolução, sendo o conhecimento, a teoria revolucionária, uma arma de luta contra a alienação. Lukács (2003) aponta que o Materialismo histórico tinha para o proletariado um valor muito maior do que simplesmente o de um método de pesquisa científica:

$$
\begin{aligned}
& \text { Ele era um dos mais } \\
& \text { importantes dentre todos } \\
& \text { os seus instrumentos de } \\
& \text { luta. Pois a luta de classes } \\
& \text { do proletariado } \\
& \text { significava, ao mesmo } \\
& \text { tempo, o despertar de sua } \\
& \text { consciência de classe. Mas } \\
& \text { - despertar dessa } \\
& \text { consciência apresentava- } \\
& \text { se por toda parte ao } \\
& \text { proletariado como } \\
& \text { consequência do } \\
& \text { conhecimento da } \\
& \text { verdadeira situação, do } \\
& \text { contexto histórico } \\
& \text { efetivamente existente. } \\
& \text { (LUKÁCS, 2003, p.415). }
\end{aligned}
$$

Este se constituiu um dos eixos centrais do método de Marx, compreender a sociedade burguesa em todas as suas manifestações, sendo que a categoria mais desenvolvida possibilitaria compreender a menos desenvolvida e, com isso, trilhar possibilidades de transformação.

Ao se deslocar da crítica da filosofia para a crítica da economia política, Marx deixa claro seu objeto de pesquisa: a sociedade burguesa "o produto da ação recíproca dos homens" (MARX, 2006, p. 1), que existe objetivamente numa realidade material aparente, que necessita ser superada para alcançar a sua essência. Em uma de suas cartas em defesa do caráter materialista e histórico da produção humana, Marx (2006, p. 1, grifo do autor) assinala: recíproca dos homens. São os homens livres de escolher esta ou aquela forma social? De modo algum. Considere-se um certo estado de desenvolvimento das faculdades produtivas dos homens e ter-se-á tal forma de comércio e de consumo. Considerem-se certos graus de desenvolvimento da produção, do comércio, do consumo e ter-se-á tal forma de constituição social, tal organização da família, das ordens ou das classes, numa palavra, tal sociedade civil. Considerese tal sociedade civil e terse-á tal Estado político, que não é mais do que a expressão oficial da sociedade civil. [...] É desnecessário acrescentar que os homens não são livres árbitros das suas forças produtivas - as quais são a base de toda a sua história - pois toda a força produtiva é uma força adquirida, o produto de uma atividade anterior. Assim, as forças produtivas são o resultado da energia prática dos homens, mas esta própria energia está circunscrita pelas condições em que os homens se encontram situados, pelas forças produtivas já adquiridas, pela forma social que existe antes deles, que eles não criam, que é o produto da geração anterior. Pelo simples fato de que toda a geração posterior encontra forças produtivas adquiridas pela geração anterior, que lhe servem como matériaprima de nova produção, forma-se uma conexão [connexité] na história dos homens, forma-se uma história da humanidade, que é tanto 
mais a história da humanidade quanto as forças produtivas dos homens, e por consequência as suas relações sociais, tiverem crescido. Consequência necessária: a história social dos homens nunca é senão a história do seu desenvolvimento

individual, quer eles tenham consciência disso quer não a tenham. As suas relações materiais formam a base de todas as suas relações.

Nesta obra, assim como nas discussões encontradas na Ideologia Alemã, Marx (2006) afirma mais uma vez que a materialidade histórica constitui-se como chave para a compreensão da sociedade e das relações estabelecidas. A história produzida pela humanidade só pode justificar-se pela história materializada pelas gerações precedentes, numa relação dialética entre o ontem e o hoje, sendo a produção material efetiva a chave para compreender a dinâmica social e suas especificidades. Neste sentido, Marx (2006) busca analisar a sociedade burguesa como a organização histórica mais desenvolvida, um conjunto de processos em constante transformação, no qual os homens transformam a sua realidade, seu modo de produção e suas relações sociais e, com esse movimento, transformam a si próprios.

Ao tratar sobre a Economia Política nos Manuscritos econômico-filosóficos de 1844, Marx (2004) realiza uma crítica de como estava sendo tratada a teoria na compreensão da realidade: "A economia nacional parte do fato dado e acabado da propriedade privada. Não nos explica o mesmo. Ela percebe o processo material da propriedade privada, que passa, na realidade, por fórmulas gerais, abstratas, que passam a valer como leis para ela" (MARX, 2004, p. 79). Para o autor, a compreensão total do fenômeno se daria somente pela compreensão de todos os fatores relacionados, o que ele já havia esclarecido também na obra Miséria da Filosofia (2009).

Com base no aprofundamento dos seus estudos anteriores, Marx escreve em 1857 a célebre "Introdução", em que sua concepção teórico-metodológica surge com clareza, no intuito de apreender a totalidade das relações, dos homens, da produção e de suas interrelações. Marx (2008) esclarece que ao tratar da Economia Política, ao estudar determinado país, aparentemente o procedimento correto seria começar pelo concreto, porém ele logo afirma um equívoco existente, pois não se pode apropriar do concreto de forma imediata, pois este é só uma representação caótica do todo. Nas palavras do autor:

Parece mais correto começar pelo que há de concreto e real nos dados; assim, pois, na economia, pela população, que é a base e sujeito de todo o ato social da produção. Todavia, bem analisado, esse método seria falso. A população é uma abstração se deixo de lado as classes que a compõem. Essas classes são, por sua vez, uma palavra sem sentido se ignoro os elementos sobre os quais repousam, por exemplo: o trabalho assalariado, o capital etc. Esses supõem a troca, a divisão do trabalho, os preços etc. $\mathrm{O}$ capital, por exemplo, não é nada sem trabalho assalariado, sem valor, dinheiro, preços etc. Se começasse, portanto, pela população, elaboraria uma representação caótica do todo e, por meio de uma determinação mais estrita, chegaria analiticamente, cada vez mais, a conceitos mais simples; do concreto representado chegaria a abstrações cada vez mais tênues, até alcançar as determinações mais simples. Chegado a esse ponto, teria que voltar a fazer a viagem de modo inverso, até dar de novo com a população, mas dessa vez não como uma representação caótica de um todo, porém como uma rica totalidade de determinações e relações 
diversas (MARX, 2008a, p. 258).

O primeiro método apresentado concretiza-se numa determinação abstrata, pois os fenômenos são simplesmente a representação caótica do todo. Marx (2008a) demonstra que a população é apenas uma abstração, ou seja, sua análise por si só não seria suficiente para romper com a visão caótica do fenômeno estudado. Já no segundo método, as determinações abstratas conduzem à reprodução do concreto por meio do pensamento, que no plano intelectual reconstrói a complexidade das relações que compõem o campo da realidade, o qual constitui o objeto de pesquisa. Assim, "o concreto é concreto, porque é a síntese de muitas determinações, isto é, unidade do diverso. Por isso, o concreto aparece no pensamento como o processo da síntese, como resultado, não como ponto de partida, embora seja o verdadeiro ponto de partida [...]" (MARX, 2008a, p. 258-259).

Este movimento de análise preconizado por Marx (2008a) aponta a necessidade de identificar os determinantes que influenciam a origem e desenvolvimento do fenômeno estudado, partindo do concreto simples (a visão caótica do todo) e por meio das análises e abstrações, chegar a categorias cada vez mais simples. Assim, ao olhar novamente para o fenômeno, torna-se possível percebê-lo em toda sua totalidade (o concreto pensado) e, por meio deste movimento dialético, o conhecimento é transformado e incorporado à prática histórica e social dos homens.

\section{PEDAGOGIA HISTÓRICO-CRÍTICA: UMA TEORIA DIALÉTICA DA EDUCAÇÃO}

O Marxismo em si não se constitui uma teoria pedagógica, no entanto, fornece categorias fundamentais para a compreensão da realidade social e seus desdobramentos na educação escolar. O movimento apreendido pelo método de análise da realidade social é o mesmo movimento preconizado por Saviani (2011) ao propor a Pedagogia Histórico-Crítica.

A tarefa de uma Pedagogia inspirada no Marxismo implica para Saviani (2012) em uma concepção de mundo materialista histórica e dialética, que apreende uma base ontológica, epistemológica e metodológica. Apropriando-se dessa concepção, trataria de incorporar este conhecimento à realidade social, ou seja, reconstruir diretrizes que possibilitam a reorganização do trabalho educativo, finalidades e objetivos da educação e das instituições formadoras, dos conteúdos, procedimentos que darão início a um novo movimento de desenvolvimento educativo, objetivando uma nova sociedade e um novo homem.

Ao compreender a educação como o ato de produzir em cada indivíduo singular a humanidade que é produzida direta e intencionalmente pelo conjunto dos homens, Saviani $(2008 ; 2011)$ destaca a necessidade de uma teoria da educação interessada em articular os conhecimentos escolares e as necessidades humanas da classe trabalhadora, considerando que "[...] o dominado não se liberta se ele não vier a dominar aquilo que os dominantes dominam. Então, dominar o que os dominantes dominam é condição de libertação" (SAVIANI, 2008, p. 45).

Para tanto, a Pedagogia Histórico-Crítica que foi assim denominada a partir de 1984, tem como objetivo desenvolver uma pedagogia concreta, como via de superação da pedagogia tradicional e moderna, ou seja, escolanovista. (SAVIANI, 2012), uma teoria comprometida com a formação de "[...] indivíduos reais não apenas no que diz respeito ao que eles são, mas principalmente àquilo que eles podem vir a ser" (DUARTE, 2001, p. 30).

Serão métodos que estimularão a atividade $\mathrm{e}$ iniciativa dos alunos sem abrir mão, porém, da iniciativa do professor; favorecerão o diálogo dos alunos entre si e com o professor, mas sem deixar de valorizar o diálogo com a cultura acumulada historicamente; levarão em conta os interesses dos alunos, os ritmos de aprendizagem e o desenvolvimento

psicológico, mas sem perder de vista a sistematização lógica dos conhecimentos, sua ordenação e gradação para efeitos do processo de transmissãoassimilação dos conteúdos cognitivos. (SAVIANI, 2008, p. 56). 
Saviani (2008; 2012) esclarece, porém, que o método por ele preconizado não pressupõe a somatória de métodos tradicionais e métodos novos, sua proposta está estritamente vinculada a um posicionamento frente à sociedade. A prática social se constitui como ponto de partida e de chegada da prática educativa. Assim, o trabalho educativo realiza um processo de mediação, que busca por meio do conhecimento historicamente acumulado, possibilitar aos alunos a superação de uma inserção acrítica para uma inserção crítica e intencional na prática social (OLIVEIRA; DUARTE, 1986; SAVIANI, 2008).

A mediação docente torna-se efetiva nos momentos intermediários do método, que consiste na tomada de consciência dos principais problemas colocados frente à prática social (problematização), na apropriação dos instrumentos teóricos e práticos necessários para a compreensão e solução dos problemas levantados (instrumentalização) e na incorporação dos elementos apropriados durante o trabalho pedagógico na própria vida dos alunos (catarse). (SAVIANI, 2008).

Neste sentido, "o ponto de partida do ensino não é a preparação dos alunos, cuja iniciativa é do professor (pedagogia tradicional), nem a atividade, que é de iniciativa dos alunos (pedagogia nova).", mas constitui-se a prática social que é comum para professores e alunos. Porém, torna-se necessário esclarecer que, mesmo em uma prática social comum, professores e alunos se encontram em diferentes níveis de compreensão, tanto do conhecimento como da experiência prática em sociedade (SAVIANI, 2008).

No início o professor apresenta uma síntese do conhecimento, pois de alguma forma já vivenciou o conteúdo abordado em sua prática social, porém esta síntese ainda será enriquecida no decorrer do processo pedagógico. Já os alunos apresentam uma visão sincrética do conteúdo em questão, pois por mais que possam conhecer sobre o tema, sua própria condição de aluno impossibilita no ponto de partida, uma articulação com a experiência pedagógica que será socializada pelo professor (SAVIANI, 2008).

O segundo passo "[...] não seria a apresentação de novos conhecimentos por parte do professor (pedagogia tradicional) nem 0 problema como um obstáculo que interrompe a atividade dos alunos (pedagogia nova)" (SAVIANI, 2008 , p. 57, grifo do autor), mas superando estas concepções, a problematização, apresenta-se como um momento chave na transição entre a prática cotidiana e o conhecimento científico, pela identificação dos principais problemas postos pela prática social e que necessitam ser apropriados no âmbito do conhecimento sistematizado.

O terceiro passo chamado de instrumentalização "[...] não coincide com a assimilação de conteúdos transmitidos pelo professor por comparação com conhecimentos anteriores (pedagogia tradicional) nem com a coleta de dados (pedagogia nova) [...]" (SAVIANI, 2008 , p. 57, grifo do autor), mas cabe neste momento, a apropriação de instrumentos teóricos e práticos que encaminhe o sujeito na busca por respostas aos problemas levantados na problematização. Neste momento, o docente irá direcionar o aluno por meio da exposição do conteúdo ou de outras formas, para que o mesmo rompa com uma visão sincrética e se aproprie de instrumentos que oportunizem um posicionamento crítico frente ao conhecimento elaborado.

O quarto passo denominado de catarse "[...] não será a generalização (pedagogia tradicional) nem a hipótese (pedagogia nova)" (SAVIANI, 2008, p. 57, grifo do autor), mas sim a expressão elaborada, a síntese de uma nova compreensão da prática social, ou seja, a manifestação do conhecimento apreendido. Assim, podemos compreender a relação estabelecida no processo educativo: a passagem da síncrese à síntese, a compreensão da totalidade dos fenômenos em termos tão elaborados como estava para o professor.

0 quinto passo que é o retorno à prática social, "não será a aplicação (pedagogia tradicional) nem a experimentação (pedagogia nova). O ponto de chegada é a própria prática social, compreendida agora não mais em termos sincréticos pelos alunos" (SAVIANI, 2008, p. 58). Torna-se perceptível uma transformação do sujeito frente à prática social, que se constituindo elemento objetivo e ativo na sociedade, transforma-se e propõe possibilidades de transformações na própria prática (SAVIANI, 2008).

$\mathrm{Na}$ busca por orientar a ação docente em prol de conduzir-se dialeticamente neste processo, encontramos em Gasparin (2012) uma proposta Didática para o planejamento do processo de ensino e aprendizagem nesta perspectiva, à qual intitulou ser "Uma didática para a Pedagogia Histórico-Crítica". Nas palavras 
de Saviani esta obra apresenta-se como uma forma possível de traduzir os princípios da Pedagogia Histórico-Crítica, somando-se ao esforço comum empreendido na implementação prática desta teoria, o que nas palavras de Gasparin (2012, p. 3) se traduz em "[...] caminhar da realidade social, como um todo, para a especificidade teórica da sala de aula e desta para a totalidade social novamente, tornando-se possível um rico processo dialético de trabalho pedagógico".

Ao analisar alguns elementos presentes na proposta didática desenvolvida por Gasparin (2002), Marsiglia, Martins e Lavoura (2019) destacam a importância dessa obra para o avanço da construção coletiva da pedagogia histórico-crítica, porém apresentam os equívocos da referida. Os autores destacam que a forma como Gasparin se apropriou do método dialético e do movimento de superação da síncrese à síntese pela mediação da análise, reduz o fundamento do método a uma aligeirada e simplificada concepção de práticateoria-prática, gerando assim formalizações inadequadas para a didática histórico-crítica. Apontam ainda que no que se refere ao ponto de partida da prática pedagógica, a formulação metodológica de Gasparin (2012) equivoca-se ao considerar que ela se ocupa de um levantamento sobre a vivência prática e imediata do aluno, tendo em vista que o próprio Saviani (2011) afirma a necessidade de conduzir o trabalho educativo com foco no aluno concreto, que sintetiza as relações sociais e se apropria da cultura para compreender a sociedade na qual está inserido.

Assim, buscar alternativas para a educação pressupõe analisar a sociedade sob uma perspectiva crítica, sendo os estudos de Marx (1996a, 1996b, 2004, 2008a, 2008b, 2009) e Marx e Engels (2007) fundamentos pertinentes para compreendermos a situação atual do mundo capitalista e vislumbrarmos mudanças. Entendemos ainda que, apropriar-se destas reflexões e incorporá-las à educação é um trabalho árduo, os quais estudiosos como Saviani (2008; 2011) têm se empenhado e apresentado encaminhamentos valiosos que incorporam 0 Materialismo Histórico-Dialético e a Pedagogia Histórico-Crítica como possibilidade efetiva para a ação docente.

Duarte $(2015$, p.9) afirma que "[...] uma das características elucidadas pela Pedagogia Histórico-Crítica reside na relação entre o trabalho educativo e a formação/transformação da concepção de mundo de alunos e professores". O caminho deste processo refere-se à própria efetivação do trabalho educativo com a totalidade do conhecimento científico, artístico e filosófico "fundamentado na concepção de mundo materialista, histórica e dialética". (DUARTE, 2015, p.15). A partir de uma base teórica consistente o professor é instrumentalizado para apropriar-se da riqueza produzida pela humanidade, considerando sua dimensão histórica, social, política, econômica, ideológica, psicológica, para que, ao final do processo, haja a compreensão do todo, da própria realidade social. Neste sentido, o Materialismo Histórico-Dialético apresenta-se juntamente com a Pedagogia Histórico-Crítica como movimento teórico-metodológico pertinente para o processo de formação docentediscente.

Saviani (2008) aponta que os mecanismos acionados como meio de adaptação aos anseios capitalistas podem ser confundidos como anseios da classe dominada. Neste sentido, enfatiza a necessidade de avançar na compreensão da natureza específica da educação e de suas complexas mediações que se inserem contraditoriamente na sociedade capitalista. Trata-se de engajar-se na luta contra a seletividade, discriminação e o rebaixamento do ensino às camadas populares. Isto significa que a escola, por meio de sua função própria de socialização do conhecimento elaborado exercida pelos professores, tem condições efetivas de garantir aos trabalhadores um ensino de melhor qualidade, possível dentro das condições históricas atuais.

Essa defesa implica a prioridade de conteúdo. Os conteúdos são fundamentais e sem conteúdos relevantes, conteúdos significativos, a aprendizagem deixa de existir, ela transforma-se num arremedo, ela transforma-se numa farsa. Parece-me, pois, fundamental que se entenda isso e que, no interior da escola, nós atuemos segundo essa máxima: a prioridade de conteúdos, que é a única forma de lutar contra a 
farsa do ensino. Por que esses conteúdos são prioritários? Justamente porque o domínio da cultura constitui instrumento indispensável para a participação política das massas. Se os membros das camadas populares não dominam os conteúdos culturais, eles não podem fazer valer os seus interesses, porque ficam desarmados contra os dominadores, que se servem exatamente desses conteúdos culturais para legitimar e consolidar a sua dominação. (SAVIANI, 2008, p. 45).

Tomada como dimensão da própria prática social, uma educação comprometida em viabilizar o saber elaborado em sua totalidade, busca pelas esferas do saber, empreender "a crítica à educação burguesa evidenciando seus mecanismos e desmistificando sua justificação ideológica" (SAVIANI, 2009, p. 114) e ao mesmo tempo "reorganizar a prática educativa de modo a viabilizar, por parte das camadas dominadas à frente o proletariado, 0 acesso ao saber elaborado." (SAVIANI, 2009, p. 114). Assim, o processo de transmissão-assimilação do saber elaborado tem como referência aquilo que se firmou como clássico, e este pode se constituir num critério útil para delimitar os conteúdos imprescindíveis ao trabalho educativo. (SAVIANI, 2011).

\section{CONCLUSÕES}

Sintetizamos por meio do estudo da Pedagogia Histórico-Crítica que, uma das formas de promover o saber elaborado, consiste em viabilizar o acesso aos bens culturais produzidos pela humanidade. Pensar na formação humana por meio do trabalho educativo, como ato de produzir direta e intencionalmente nos alunos a humanidade produzida historicamente pelo conjunto dos homens, pressupõe uma fundamentação que eleve o sujeito aluno à apropriação da cultura elaborada historicamente, o que pode vislumbrar uma nova percepção da sua realidade social.

Por mais que esteja claro que, muitas vezes, a escola tem prestado serviço ao capital como forma de adaptação dos indivíduos, contraditoriamente, ela também está vinculada à formação do trabalhador alienado pelas condições impostas pela sociedade capitalista, e é nesta relação que acreditamos ser possível um processo de transformação do sujeito frente à sua prática social. Neste sentido, a relação explicita entre educação e trabalho põe-se em contradição com a ordem capitalista, em que os meios de produção são propriedades privadas da classe dominante. Na medida em que o saber teórico e prático é apropriado pelos trabalhadores (dominados pela sociedade capitalista), estes passam a ser proprietários dos meios de produção, e assim, desenvolvem meios para compreender as múltiplas relações postas na sociedade. Este é o ponto de partida para o posterior desenvolvimento de uma concepção de mundo materialista, histórica e dialética.

No entanto, esta concepção dialética perpassa primeiramente pela ação do professor, que na sociedade de classes está submetido constantemente à fragmentação do trabalho material e à alienação do sistema que manipula, muitas vezes, seu desenvolvimento intelectual e sua prática pedagógica. Assim, se o trabalho educativo se reduz somente às condições materiais da vida do professor, o ensino será consequentemente uma atividade alienada. Este aspecto se torna ainda mais grave no exercício da docência, pois a alienação do trabalhador também gerará alienação no produto do seu trabalho, o desenvolvimento do aluno. Visto deste modo, $\mathrm{o}$ trabalho educativo estaria desprovido de meios para cumprir a função que Ihe é devida.

Porém, ao fundamentar-se em uma perspectiva crítico-dialética, compreendemos que o trabalho do professor não pode reduzir-se a um simples meio de reprodução de sua existência, mas que precisa efetivar-se como elemento mediador entre o cotidiano e as esferas não cotidianas da prática social do aluno. Estes fundamentos expressam a problemática da sociedade atual e orientam para a resistência dos discursos presentes na sociedade capitalista, que descaracterizam o papel da escola e a função do trabalho educativo. A Pedagogia Histórico-Crítica possibilita reafirmar nas ações teórico/práticas os objetivos da educação tal como postulamos ao longo do texto, que se refere tanto em identificar os elementos culturais para a humanização do homem, como em descobrir melhores caminhos para atingir este objetivo. 
A escola necessita estar direcionada para a formação do aluno concreto. O aluno empírico, pautado no senso comum vê na educação somente as possibilidades postas pelo mercado de trabalho, a fragmentação do conhecimento e de si mesmo, porém o aluno concreto, situado em uma sociedade com necessidades de caráter social, histórico, cultural, político, afetivo, só pode encontrar resposta às problemáticas postas em sua prática social por meio do conhecimento sistematizado. Somente olhando para o aluno concreto é que podemos pensar na educação como transformação da realidade e da concepção de mundo, pois o movimento de prática-teoria-prática proposto pela Pedagogia Histórico-Crítica não pode efetivar-se em um contexto que se limita às necessidades imediatas do aluno.

Por mais que a sociedade atual se organize de forma a impedir a plena socialização das dimensões que perpassam o conhecimento humano, acreditamos que é possível lutar para que se efetivem ao máximo, as possibilidades dos conhecimentos científicos, artísticos e filosóficos. O conhecimento, neste sentido, torna-se caminho para a consciência de mundo, que direciona a uma ação humana transformadora.

Em uma visão materialista histórica e dialética entendemos que a formação, tanto de professores como de alunos, constitui-se um processo de transformação da possibilidade em realidade. Ao compreender conscientemente a necessidade de efetuar transformações, de engajar-se na luta por uma educação de qualidade, professores e alunos podem objetivar uma nova realidade social. Sabemos que conduzir o trabalho educativo em uma perspectiva Histórico-Crítica não é uma tarefa fácil, mas acreditamos que é uma proposta real para aqueles que buscam uma formação consciente e fomentá-la é a melhor alternativa para viabilizar o seu conhecimento e implantação.

\section{REFERÊNCIAS}

ANDERY, M. A. P. A; SÉRIO, T. M. A. P. A prática, a História e a construção do conhecimento: Karl Marx . In: ANDERY, M. A. P. A; MICHELETTO, N.; SÉRIO, T. M. P.; RUBANO, D. R.; MOROZ, M.; SILVIA, M. E. P.; GIOIA, C.; Gianfaldoni, M.; SAVIOLI, M. S.; ZANOTTO, M. De L. Para compreender a ciência: uma perspectiva histórica. 5. ed. Rio de Janeiro: Espaço e Tempo, 1994. p. 402-434.
CAMBI, F. História da pedagogia. Tradução de Álvaro Lorencini. São Paulo: UNESP, 1999.

DUARTE, Newton. Educação escolar, teoria do cotidiano e a escola de Vigotski. 3. ed. Campinas: Autores associados, 2001.

DUARTE, N. Sociedade do conhecimento ou sociedade das ilusões? Quatro ensaios críticodialéticos em filosofia da educação. Campinas, SP: Autores Associados, 2008.

DUARTE, N. A importância da concepção de mundo para a educação escolar: porque a Pedagogia Histórico-Crítica não endossa o silêncio de Wittgenstein. Germinal: Marxismo e Educação em Debate, Salvador, v. 7 n. 1, p. 8-25, jun. 2015. Disponível

em: http://www.portalseer.ufba.br/index.php/revista germinal/article/view/12808. Acesso em: $20 \mathrm{dez}$. 2018. https://doi.org/10.9771/gmed.v7i1.12808

ENGELS, F. Sobre o papel do trabalho na transformação do macaco em homem. 1876. Disponível em: http://www.psb40.org.br/bib/b15.pdf. Acesso em: 20 fev. 2016.

GASPARIN, J. L. Uma didática para a pedagogia histórico-crítica. Campinas: Autores Associados, 2012.

GAMBOA, S. S. Os projetos de pesquisa: alguns fundamentos lógicos necessários. In BRYAN, N.; MIRANDA, E. (Editores). (Re) pensar laeducación pública: aportes desde Argentina y Brasil, Córdoba: Ed Universidad Nacional de Córdoba, 2011. p.121-150.

LOMBARDI, J.; SAVIANI, D.; SANFELICE, J. L. (Orgs.). Capitalismo, trabalho e educação. Campinas, Autores Associados, 2002.

LUKÁCS, G. História e consciência de classe. São Paulo: Martins Fontes, 2003.

MARSIGLIA, A. C. G; MARTINS, L; LAVOURA, T. N. Rumo à outra didática histórico-crítica: superando imediatismos, logicismos formais e outros reducionismos do método dialético. Revista HISTEDBR On-line, v. 19, p. 128, 2019. https://doi.org/10.20396/rho.v19i0.8653380 
MARX, K. O Capital: crítica da economia política. Livro 1. V. 1. Tomo 1. (Os economistas). Tradução por Regis Barbosa e Flávio R. Kothe. Editora Nova Cultura LTDA, 1996a.

MARX, K. O Capital: crítica da economia política.Livro 1. V. 1. Tomo 2. (Os economistas). Tradução por Regis Barbosa e Flávio R. Kothe. Editora Nova Cultura LTDA, 1996b.

MARX, K. Manuscritos econômico-filosóficos. Tradução de Jesus Ranieri. São Paulo: Boitempo Editorial, 2004.

MARX, Karl. Carta a Pável V. Annenkov (em Paris). 28 de Dezembro de 1846. 2006. Disponível em: <https://www.marxists.org/portugues/marx/184 6/12/28.htm>. Acesso em: 10 fev. 2016.

MARX, K. Contribuição à Crítica da Economia Política. Tradução e Introdução de Florestan Fernandes. 2. ed. São Paulo: Expressão Popular, 2008a.

MARX. K. Manifesto do partido comunista. São Paulo: Expressão Popular, 2008b.

MARX, K. Miséria da Filosofia. São Paulo: Expressão Popular, 2009.

MARX, K. Contribuição à Crítica da filosofia do direito de Hegel. Introdução. São Paulo: Expressão Popular, 2010.

MARX, K. ENGELS, F. A ideologia alemã. Tradução Luiz Claudio de Castro e Costa.3. ed. São Paulo: Martins Fontes, 2007.

OLIVEIRA, B.; DUARTE, N. A socialização do saber escolar. São Paulo: Cortez: Autores Associados, 1986.

PAULO NETTO, João Paulo. 0 que é Marxismo. 9 ed. São Paulo: Brasiliense, 2006.

PAULO NETTO, J. P. Introdução ao estudo do método de Marx. 1 ed. São Paulo: Expressão Popular, 2011.

RUIZ, Maria José Ferreira. A escola estatal capitalista e a educação do trabalhador. Revista Trabalho e Educação, Belo Horizonte, v.23 , n.1, p. 119-137, jan-abr. 2014.
SAVIANI, D. Trabalho e educação: fundamentos ontológicos e históricos. Revista Brasileira de Educação, Rio de Janeiro, v. 12, n. 34, jan./abr. $2007 . \quad$ Disponível em: http://www.scielo.br/pdf/rbedu/v12n34/a12v12 34.pdf. Acesso em: 20 abr. 2016. https://doi.org/10.1590/S1413$\underline{24782007000100012}$

SAVIANI, D. Escola e democracia.(Coleção educação contemporânea). Campinas: Autores Associados, 2008.

SAVIANI, Dermeval. Modo de produção e a Pedagogia Histórico-Crítica. Germinal: Marxismo e Educação em Debate, Londrina, v. 1, n. 1, p. 110-116, jun. 2009. Disponível em: http://www.portalseer.ufba.br/index.php/revista germinal/article/viewFile/9844/7129. Acesso em: 10 nov. 2015.

SAVIANI, D. Pedagogia histórico-crítica: primeiras aproximações. 11. ed. Campinas: Autores Associados, 2011.

SAVIANI, D. Origem e desenvolvimento da pedagogia histórico-crítica. In: COLÓQUIO INTERNACIONAL MARX E ENGELS - "Marxismo e Educação: Fundamentos Marxistas da Pedagogia Histórico-Crítica", 7, 2012, Campinas. Anais Eletrônicos... Campinas: IFCH-UNICAMP, 2012. Mesa Redonda. Disponível em: http://www.ifch.unicamp.br/formulario cemarx/ selecao/2012/trabalhos/Demerval\%20Saviani.pdf . Acesso em: 4 ago. 2015.

SAVIANI, D. Sobre a natureza e especificidade da educação. Germinal: Marxismo e Educação em Debate, Salvador, v.7 n. 1, p. 286-293, jun. 2015a. Disponível em: http://www.portalseer.ufba.br/index.php/revista germinal/article/view/13575/951. Acesso em: 20 dez. 2015. https://doi.org/10.9771/gmed.v7i1.13575

SAVIANI, D. O conceito dialético de mediação na pedagogia histórico-crítica em intermediação com a psicologia histórico-cultural. Germinal: Marxismo e Educação em Debate, Salvador, v. 7, n. 1, p. 26-43, jun. 2015b. Disponível em: http://www.portalseer.ufba.br/index.php/revista germinal/article/view/13575/951. Acesso em: 20 dez.

2015. 